\title{
Cataract following electric shock - Case report
}

\section{Khadka S', Byanju R², Ranabhat S $^{3}$}

${ }^{1}$ Simanta Khadka, Ophthalmologist; ${ }^{2}$ Raghunandan Byanju, Professor; ${ }^{3}$ Sudha Ranabhat, Third year resident, Department of Vitreo-Retinal Diseases and Surgery, Bharatpur Eye Hospital, Bharatpur, Chitwan, Nepal.

\begin{abstract}
Ocular trauma is the under-recognized cause of unilateral blindness particularly in developing nations.The growing demand on generated electricity has also led to increase in electricity related occupational trauma. We report a case of bilateral cataract in a 22 years professional electrician. He survived a high voltage electric shock and sustained burn injury on the right side of his head. Ocular examination revealed typical anterior as well as posterior subcapsular cataract in right eye and visually insignificant early anterior subcapsular vacuoles in the left eye. There was a significant difference in lenticular opacification density in between these two eyes. Uneventful phacoemulsification and foldable posterior chamber intraocular lens implantation was performed in the right eye and the sufferer was rehabilitated with normal best corrected visual acuity. The possibility of ocular complications and importance of ocular screening is emphasized in the survivors of electrical injury. The lenticular opacities can be successfully managed with surgery, however the final visual acuity depends on damage to other vital ocular structures. The clinical features, pathogenic mechanism of these opacities and review of the literatures are discussed.
\end{abstract}

Key words: Electric cataract; Electrical injury; Lenticular opacities; Trauma; Visual acuity

DOI: https://doi.org/10.3126/jkmc.v8i3.29726

\section{INTRODUCTION}

$\mathrm{O}$ cular trauma generally leads to unilateral visual loss with male preponderance, notably in the developing nations. Workplace related accidents is the frequent setting for the occurrence of trauma followed by household injuries, road traffic accident, sports and leisure activities among others'.

The increasing dependency on generated electricity has also resulted in a rise in injuries due to contact with electrical current ${ }^{2}$. Electric burns can cause various ocular injuries manifesting in the form of conjunctival hyperemia, corneal opacities, uveitis, miosis, spasm of accommodation, cataract, retinal edema, papilledema, chorio-retinal necrosis/atrophy, retinal detachment and optic atrophy ${ }^{3}$. The first description of lightning induced electric cataract was reported by Saint Yves ${ }^{4}$. Similarly, cataract formation following artificially generated electrical current was demonstrated by Desbrieres

Address for correspondence

Dr. Simanta Khadka

Ophthalmologist, Department of Vitreo-Retinal Diseases and Surgery

Bharatpur Eye Hospital, Bharatpur, Chitwan, Nepal

E-mail: simantakhadka@gmail.com

ORCID: https://orcid.org/0000-0002-9161-4440 and $B a r g y^{5}$. The incidence of electrical cataract ranges from 0.7 to $8.0 \%^{6}$. Visual loss from accidental exposure to artificially generated electric current has become accountable to workmen's compensation claims as well and is comparable to lightning injury ${ }^{7}$. However, only few cases of electrical cataract have been reported in the literature, probably because only few patients survive the high voltage of electric current that induces cataract formation ${ }^{8}$.

We present a case of a young adult male with bilateral traumatic cataract who survived high tension electrocution injury and the patient has been visually rehabilitated following cataract surgery in one eye.

\section{CASE DESCRIPTION}

A 22 years male, electrician by profession presented to our outpatient department with complain of gradual diminution of distant vision in right eye (RE) since three months which was worse in bright light. The patient survived a high voltage electric shock (12000 Volt) two years back. He suffered from the injury while working when his head accidentally touched an exposed electric wire. He recounted an event of loss of consciousness for one and half hour along with burn injuries at right 
side of scalp and anterolateral part of right thigh and received an intensive care treatment at a nearby medical college teaching hospital over a month long duration. Patient was then left with scar at right side of scalp in the occipital region with localized bald patch and at the anterolateral part of right thigh (Figure1).

On ocular examination, the best corrected visual acuity (BCVA) in RE was 1/60 (1.78 Log MAR) not improving with pinhole and 6/9 (0.20 Log MAR) in left eye (LE). Pupils were round, regular and reactive to light in both eyes. Slit lamp biomicroscpic examination of RE showed anterior and posterior subcapsular cataract along with anterior subcapsular opacification in left eye but it was not visually significant (Figure 2). Posterior segment view
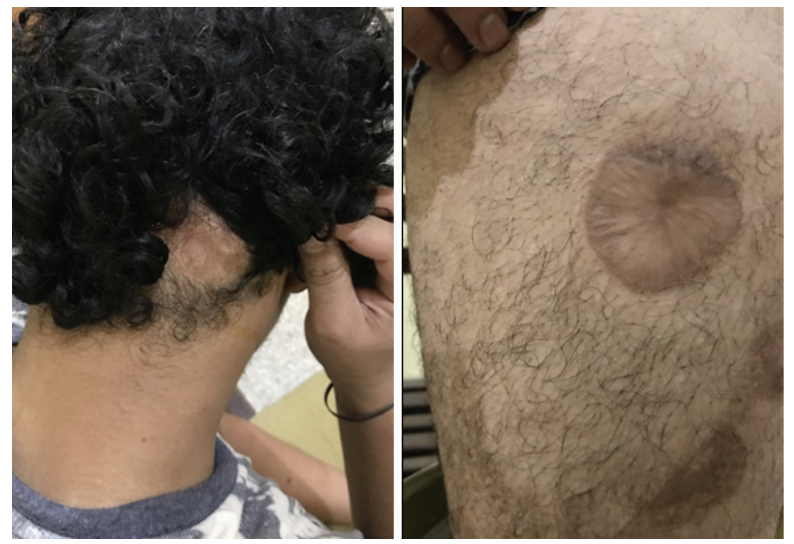

A

B

Figure 1: Scars present in the patient body. A: Entry wound with bald patch, B: Exit wound on right thigh.

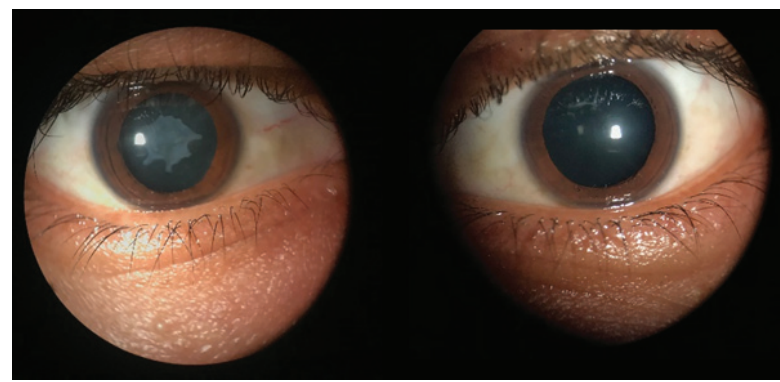

Right Eye

Left Eye

Figure 2: Slit Lamp Biomicroscopic appearance of right Anterior subcapsular cataract and left few anterior subcapsular opacifications was obscured in RE whereas LE fundus findings were within normal limit. B-scan ultrasonography revealed normal posterior segment in right eye. Intraocular pressure (IOP) was within normal range in both eyes.

Patient underwent uneventful RE phacoemulsification surgery with foldable posterior chamber intraocular lens implantation (PCIOL) in the capsular bag under topical anesthesia (Figure 3). Postoperative recovery was uneventful and patient regained BCVA of 6/6 (0.00 Log MAR) (Figure 4). RE postoperative fundus examination was possible after the surgery and found to be within normal limit (Figure 5). At the end of six months, his vision was stable and there was no further ocular complications.

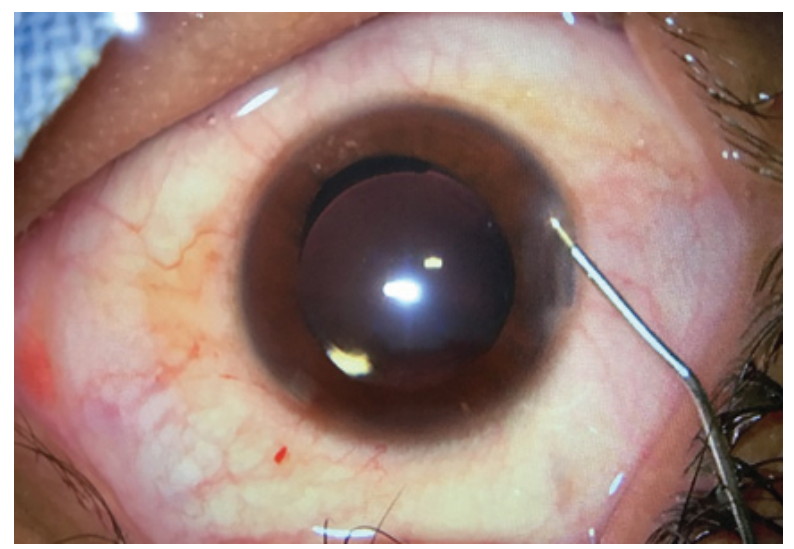

Figure 3: Intraoperative picture of the right eye at the conclusion of surgery.

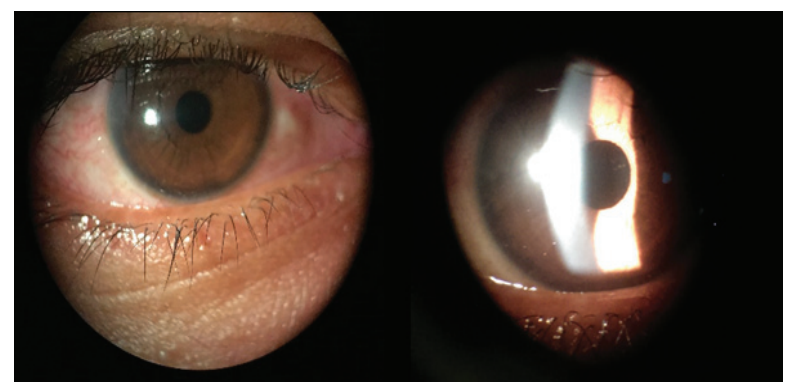

A

B

Figure 4: Post-operative picture of operated eye at A: end of one week, $B$ : end of six months. 

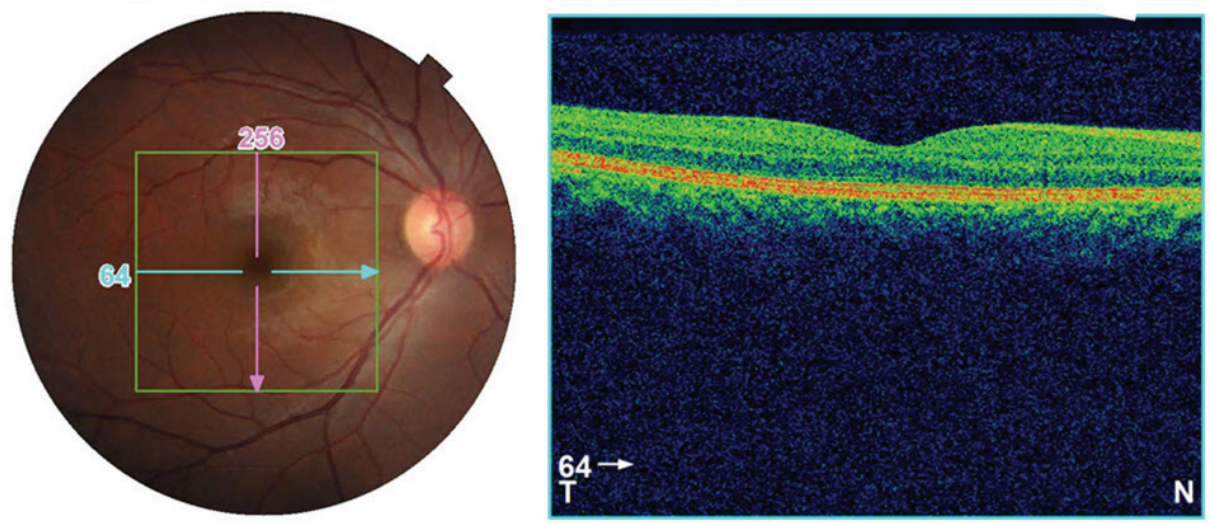

Figure 5: Normal fundus image and normal appearance of Optical Coherence Tomographic scan of right eye.

\section{DISCUSSION}

Lenticular opacities are the commonly encountered complications following high voltage electrical injury ${ }^{9}$. Ocular changes have been limited to retinal injuries to voltage less than 200 Volt $(\mathrm{V})^{10}$. Nonetheless, electric cataract occurs after shock with voltages ranging from $220 \mathrm{~V}$ to $60,000 \mathrm{~V}$. The requisite shock is of near fatal severity and is associated with unconsciousness of the injured and gross tissue damage ${ }^{11}$.The lenticular changes may develop immediately or after few days following electric injury with the latency varying from one to 18 months ${ }^{12}$, and even as long as 11 years has been affirmed in the literature ${ }^{13}$. During an electric shock, the current flows between two contact points through the body. A number of factors influence the clinical picture of electrical injury including voltage, tissue sensitivity, type of current (direct or alternating), duration of contact, area of contact and route travelled within the body ${ }^{14}$. The location of the body burns determine the points of contact with the live conductors. In the case of unilateral cataract it was found that the cataract usually developed on the side closest to the contact and, if bilateral, the earlier and more severely involved lens was on the side nearest the contact ${ }^{7}$.

Cataractogenesis following electrical shock has been reported with a variable latency period ${ }^{15}$. As the initial burn is usually life threatening condition, ocular evaluations may be delayed. Our case presented with cataract approximately after 21 months following an event surviving a high voltage electrical trauma. Exclusive lenticular involvement sparing other ocular structures is rare ${ }^{16,17}$. The points of contact with the live conductors were determined by the location of the body burns. The contact points resulted was probably due to lurching produced by violent muscular contractions. Many injuries were associated with gross tissue loss and with amputations frequently?

The earliest changes recognized in the lens after electrical injury are a collection of multiple fine vacuoles just beneath the anterior subcapsular region, usually in the mid-periphery of the lens, mandating pupillary dilatation for obvious visualization. These vacuoles may not reduce the vision instantly, nevertheless these collections present in the anterior subcapsular area show no apparent relationship to the configuration of lens fibre. Over a period of time, flake-like opacities replace these vacuoles which coalesce and migrate obscuring the visual axis ${ }^{15}, 18$. Histopathological analysis of the anterior capsule specimen obtained after continuous curvilinear capsulorrhexis revealed significant scar tissue which consisted of fibroblast proliferation and hyaloid production over the basement membrane of the anterior capsule ${ }^{19}$.

The exact pathogenesis of electric cataract is meagre. The possible mechanism is hypothesized to decreased permeability of the lens capsule, or a direct coagulative effect on the lens proteins. The other explanations could be violent contraction of the ciliary muscle causing a concussion type of cataract due to mechanical damage, or nutritional disturbance of the lens due to iritis and impaired circulation. Ultraviolet and infrared irradiation could be another possible cause leading to cataract ${ }^{18}$. The progression of the cataract varies differently from case to case. It may remain stationary for a protracted period or progress gradually to mature or hypermature cataract and may cause phacomorphic glaucoma in rare instance ${ }^{20}$. The amount and rapidity of lenticular changes bear no direct relationship to the strength of 
the current ${ }^{12}$. The lens of the younger patients is more vulnerable to damage than that of old age ${ }^{21}$.

Like any other cataract, electric cataract is managed in a similar way. Extracapsular extraction with PCIOL implantation is the preferred surgical technique ${ }^{17}$.The final visual acuity in these cases will depend upon the involvement of other ocular structures namely the retina and optic nerve. The contemporary phacoemulsification surgery followed by in the bag implantation of foldable

\section{REFERENCES}

1. Thylefors B. Epidemiological patterns of ocular trauma. Australian and New Zealand journal of ophthalmology. 1992 May;20(2):95-8 [PubMed]

2. Grewal DS, Jain R, Brar GS, Grewal SP. Unilateral electric cataract: Scheimpflug imaging and review of the literature. Journal of Cataract \& Refractive Surgery. 2007 Jun 1;33(6):1116-9 [PubMed]

3. Baranwal VK, Satyabala K, Gaur S, Dutta AK. A case of electric cataract. Medical journal, Armed Forces India. 2014 Jul;70(3):284 [PubMed]

4. Saint Yves. Les causes accidentelles, qui peuventblesser la vue..Nouveau Traite' des Maladies des Yeux, les Remedes qui y Conviennent, \& les Operations de ChirurgiequeLeursGue'risons. 1722; 368-370. (Cited by Duke-Elder S, Textbook of Ophthalmology.St. Louis, MO, Mosby, 1964; vol 6:6435-6442).

5. Desbrie'res J, Bargy M. Un cas de cataracte due a une de'charge e'lectrique industrielle. Ann Oculist (Paris). 1905;133:118-122.

6. Saffle JR, Crandall AL, Warden GD. Cataracts: a long-term complication of electrical injury. The Journal of trauma. 1985 Jan;25(1):17-21 [PubMed]

7. Long JC. Electric Cataract: A clinical and experimental study. American Journal of Ophthalmology. 1963 Jul 1;56(1):108-33 [DOI]

8. Rathi M, Bhatt N, Dhull CS, Sachdeva S, Phogat J. Electric cataract: a report of two cases and a review of the literature. The Egyptian Journal of Cataract and Refractive Surgery. 2016 Jul 1;22(2):54 [DOI]

9. Boozalis GT, Purdue GF, Hunt JL, McCulley JP. Ocular changes from electrical burn injuries: a literature review and report of cases. The Journal of burn care \& rehabilitation. 1991 Sep 1;12(5):45862 [DOI]
PCIOL resulted in stable and good visual recovery in our case.

\section{CONCLUSION}

A detailed ocular examination must be conducted to rule out possible ocular complications of electric shock. Appropriate surgical management of electric cataract will result in a good visual rehabilitation provided the eye has no other additional damage. It is mandatory for a long term close follow-up of these type of patients.

10. Geeraets WJ, Nooney Jr TW. Retinal injury due to electric current? a clinical study. Annals of ophthalmology. 1973 Mar;5(3):265

11. Long JC. Electric cataract: report of three cases. American journal of ophthalmology. 1966 May 1;61(5):1235-9 [DOI]

12. Duke-Elder S,editor. Injuries: non-mechanical injuries. System of ophthalmology. London: Henry Kimpton; 1972.14;2;813-835 [DOI]

13. Skoog T. Electrical injuries. Journal of Trauma and Acute Care Surgery. 1970 Oct 1; 10(10):816-30 [DOI]

14. Solem L, Fischer R. Strate RG. The natural history of electrical injury. J Trauma. 1977; 17:487-92 [PubMed]

15. Hanna C, Fraunfelder FT. Electric cataracts: II. Ultrastructural lens changes. Archives of Ophthalmology. 1972 Feb 1;87(2):184-91 [PubMed]

16. Raina UK, Tuli D. Bilateral electrical cataract. British journal of ophthalmology. 1999 Sep 1;83(9):1088 [DOI]

17. Reddy SC. Electric cataract: a case report and review of the literature. European journal of ophthalmology. 1999 Apr;9(2):134-8 [PubMed]

18. Fraunfelder FT, Hanna C. Electric cataracts: I. Sequential changes, unusual and prognostic findings. Archives of Ophthalmology. 1972 Feb 1;87(2):179-83 [PubMed]

19. Hashemi $H$, Jabbarvand $M$, Mohammadpour $M$. Bilateral electric cataracts: clinicopathologic report. Journal of Cataract \& Refractive Surgery. 2008 Aug 1; 34(8):1409-12 [DOI]

20. Stephen V, John SR, Chakraborty A, Chakrabarti M. Bilateral cataract following electrical injury. Kerala J Ophthalmol. 2006;18(3):252-4 [DOI]

21. Batiles M, BV M. Duane's clinical ophthalmology, Vol I, Chapter 73, Cataract-clinical types. Philadelphia, New York: Lippincott-Raven Publishers. 1996:Page no.22. 